\title{
Proposal for a modernized Iranian notifiable infectious diseases surveillance system: comparison with USA and Australia
}

\author{
F.E.F. Azar, ${ }^{7}$ N. Masoori, ${ }^{2}$ Z. Meidani ${ }^{3}$ and L. Paul ${ }^{4}$
}

$$
\begin{aligned}
& \text { اقتراح لإضفاء سمات عصرية على نظام تـرصُّد الأمر اض المعدية الواجبة الإبلاغ في إيران مقارنةً مع الو لايات المتحدة الأمريكية وأستـراليا }
\end{aligned}
$$

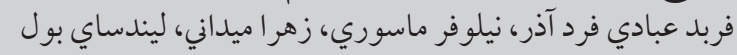

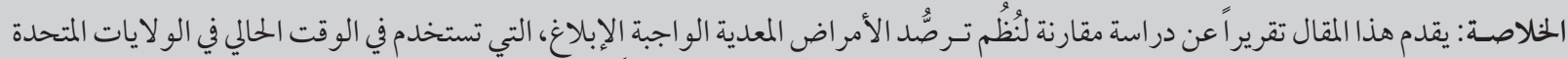

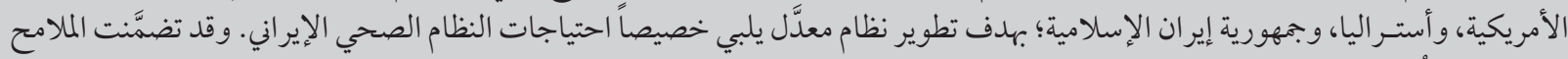

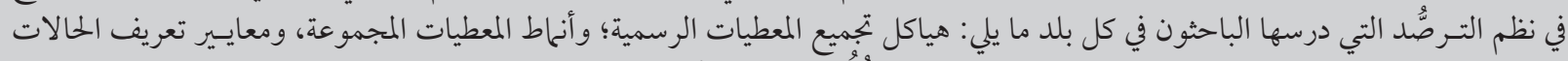

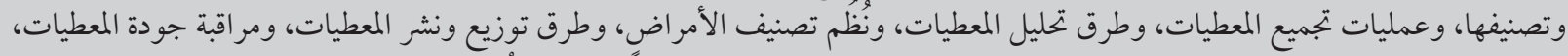

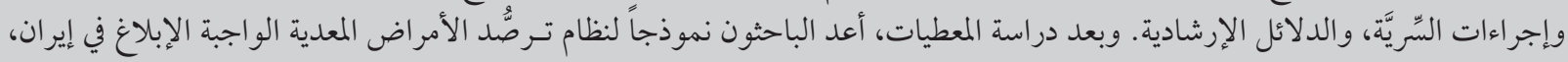

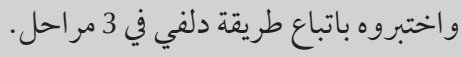

\begin{abstract}
This article reports on a comparative study of the national notifiable infectious diseases surveillance systems currently employed in the United States of America, Australia and the Islamic Republic of Iran, with the aim of developing a modified system specific to the needs of the Iranian health system. Features of the surveillance systems examined in each country included: official data gathering structures; types of data collected; case definition and classification criteria; data collection processes; data analysis methods; disease classification systems; data dissemination and distribution methods; data quality control; and confidentiality procedures and guidelines. After consolidating the data, a model for an Iranian notifiable infectious diseases surveillance system was developed and was tested by the Delphi method in 3 stages.
\end{abstract}

Proposition en vue de la modernisation du système iranien de surveillance des maladies infectieuses à déclaration obligatoire : comparaison avec les États-Unis et l'Australie

RÉSUMÉ Cet article présente une étude comparative portant sur les systèmes nationaux de surveillance des maladies infectieuses à déclaration obligatoire actuellement en place aux États-Unis, en Australie et en République islamique d'Iran. Son objectif est de réformer le système pour l'adapter aux besoins du système de santé iranien. Les caractéristiques des systèmes de surveillance étudiés dans chaque pays comprenaient: les structures de collecte de données officielles, les types de données recueillies, la définition de cas et les critères de classification, les procédés de collecte des données, les méthodes d'analyse des données, les systèmes de classification des maladies, les méthodes de diffusion et de distribution des données, le contrôle de la qualité des données et les procédures et directives relatives à la confidentialité. Après regroupement des données, un modèle de système iranien de surveillance des maladies infectieuses à déclaration obligatoire a été mis au point et testé selon la méthode Delphi en 3 étapes. 


\section{Introduction}

Despite expectations that they would eventually be eliminated from the world, a number of infectious diseases still remain at the forefront of global health concerns. The success of the eradication of smallpox [1] has unfortunately not been repeated for other diseases. Indeed, infectious diseases increasingly threaten public health and contribute significantly to the escalating costs of health care in many countries, particularly developing countries. New infectious agents are continually being discovered, while infectious diseases that have previously been controlled re-emerge in new forms or become resistant to standard treatments. In order to contain such outbreaks an efficient health surveillance system, with comprehensive, accurate and timely collection of health data, is essential.

Surveillance data can be used to inform policy-making, planning, implementation, resource allocation and for the prediction and early detection of epidemics at local, national and international level [2]. In many countries reporting of notifiable infectious diseases is mandatory, a process which is essential to the efficacy of their surveillance systems [3].

Health surveillance activities in any country are conducted within the context of social factors - such as age distribution, gender issues, lifestyle, cultural background and socioeconomic status - which may or may not be stable. Surveillance systems in developing countries are susceptible to shortcomings [4]. While every country needs to develop its own specific surveillance system tailored to the prevailing socioeconomic, political and administrative conditions, much can be learned from a study of countries that have well-established procedures and extensive organizational structures in place. Because the United States of America (USA) and Australia fulfil these criteria, they were chosen for this comparative study of the Islamic Republic of Iran's current system, which although it has improved since 1990 is nevertheless undergoing further modernization $[5,6]$.

\section{Methods}

A cross-sectional comparative study of the health surveillance systems in the USA, Australia and Islamic Republic of Iran was undertaken during 2004-05. Data for the review were gathered from a variety of sources, including library resources, the Internet and consultation with Iranian, American and Australian health professionals via interviews and email.

The following factors were reviewed for each country and are presented in the Results.

- Official data gathering structures: the mechanisms by which data are gathered; the centres that collect and consolidate data and the agencies that are responsible for reporting occurrence of notifiable disease at national, state or county and at local or district levels.

- Types of data collected and data sources: the types of demographic, laboratory and clinical data on notifable diseases that are reported to the responsible organizations; sources that contribute to the data-gathering process.

- Case definition and classification criteria: the uniform criteria used for reporting notifiable infectious diseases; case classification guidelines (e.g. "confirmed case", "probable case", "laboratory-confirmed case", "clinically compatible case", "supportive laboratory results", "epidemiologically linked case"); case definitions ("standard criteria for deciding whether a person has a particular disease or health-related condition, by specifying clinical criteria and limitations on time, place, and person") [7].
Other factors that were examined as part of the process were: data collection processes (whether the data collection is passive or active; time frames for reporting diseases; how information is transmitted to the national authority); data analysis methods (health indicators and computer software used for data analysis); disease classification systems used for international comparisons; data dissemination methods; data quality control systems; and procedures and guidelines for preserving confidentiality of patient data.

Using the comparative information tabulated here, a model for a notifiable infectious diseases surveillance system tailored to meet the unique requirements of the Iranian context was proposed. The major characteristics of the Iranian surveillance system were determined on the basis of the country's existing procedures, policies, laws and its prevailing socioeconomic, political, geographic location and administrative context.

In order to confirm the suitability of the proposed model, 58 questionnaires were distributed to infectious disease physicians, health experts, staff at Tehran and Shaheed Beheshti Medical Universities, the Iranian Centre for Disease Control and Prevention and highly qualified health information management professionals. Of the 58 questionnaires distributed, 49 were returned and the respondents' suggestions were taken into consideration.

The model was then tested by the Delphi method [8] (a technique for achieving consensus among a panel of experts) in 3 stages by consulting experts from the Iranian Centre for Disease Control and health information management professionals. The final model was analysed and verified using descriptive statistics. SPSS was used for data entry and descriptive analysis [9] of the frequency distributions of experts' agreement for the Delphi method. 


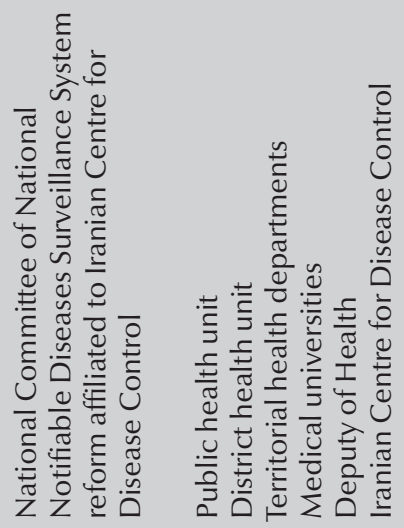

\section{Structure of national notifiable diseases surveillance systems}

In the USA reporting of notifiable diseases is mandated only at state level (Table 1) and because each state determines which diseases are notifiable within its own jurisdictions, there is some inconsistency between the states. Reporting by states to the central agency, the US Centers for Disease Control and Prevention (CDC) of the Department of Health and Human Services is voluntary. However, in compliance with the World Health Organization (WHO) international health regulations, all states must report internationally quarantinable diseases (cholera, plague and yellow fever).

In Australia the central agency for collection of notifiable disease data is the government National Notifiable Diseases Surveillance System (NNDSS) of the Department of Health and Ageing. Under this scheme, notifications are made to the state or territory health authority under the provisions of the public health legislation within their jurisdiction. At state and local levels information is collected by the state health departments (e.g. in Victoria, the Department of Human Services). Notifiable diseases must be reported in accordance with regulations.

In the Islamic Republic of Iran, the national surveillance of both communicable and noncommunicable diseases is the responsibility of the Iranian Centre for Disease Control and Prevention, which operates under the auspices of the Ministry of Health and Medical Education. This central agency is responsible for legislation, policy, norms and standards for surveillance. Data are collected from health houses, rural and urban health centres, hospitals, laboratories and the private health sector. Different disease-specific programmes manage data in specific ways [10].

\section{Types of data and data sources}

With a few variations, the 3 countries collect similar types of data. The USA obtains data from a large number of sources. In Australia, all health care practitioners who are qualified 


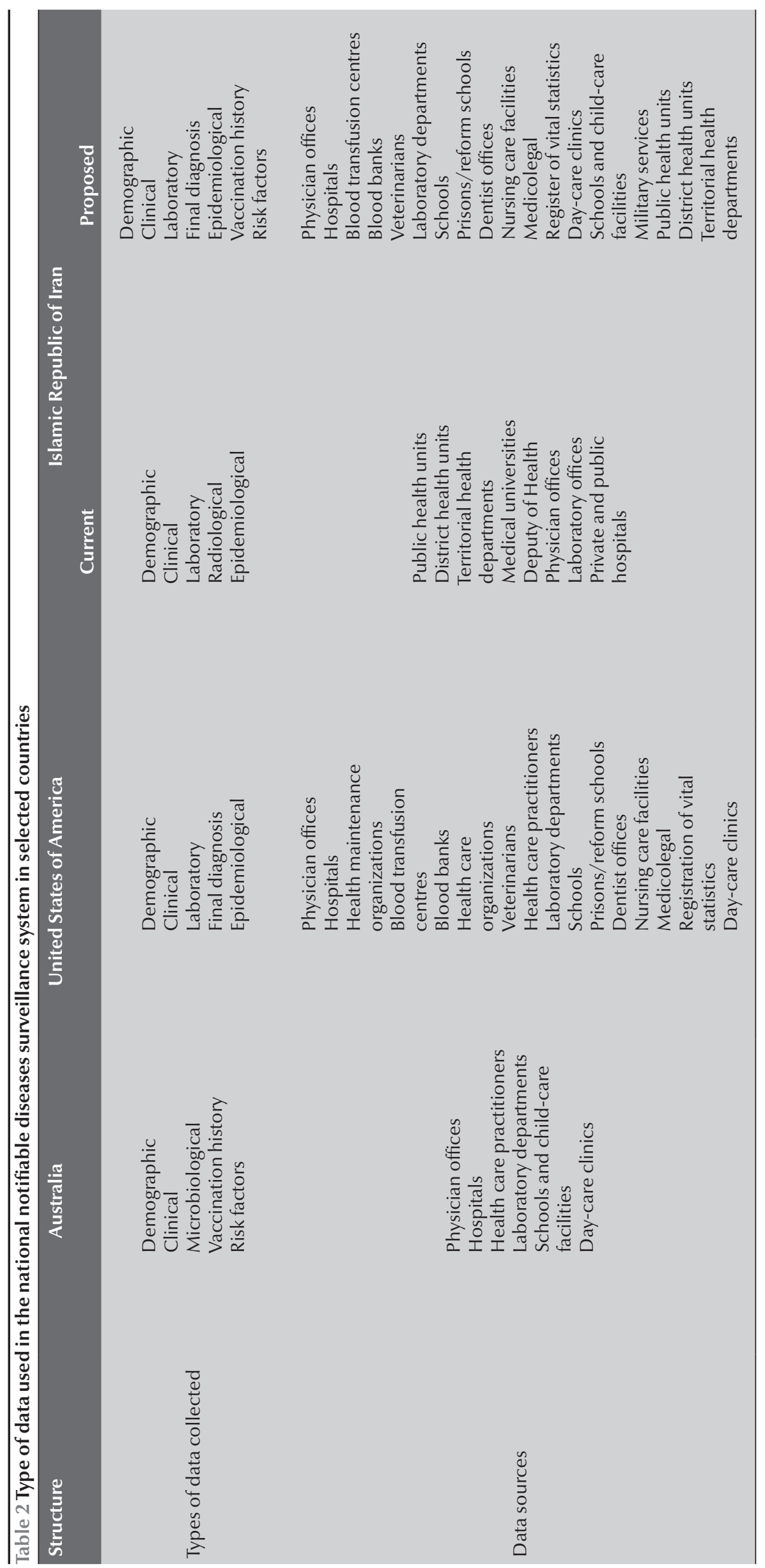



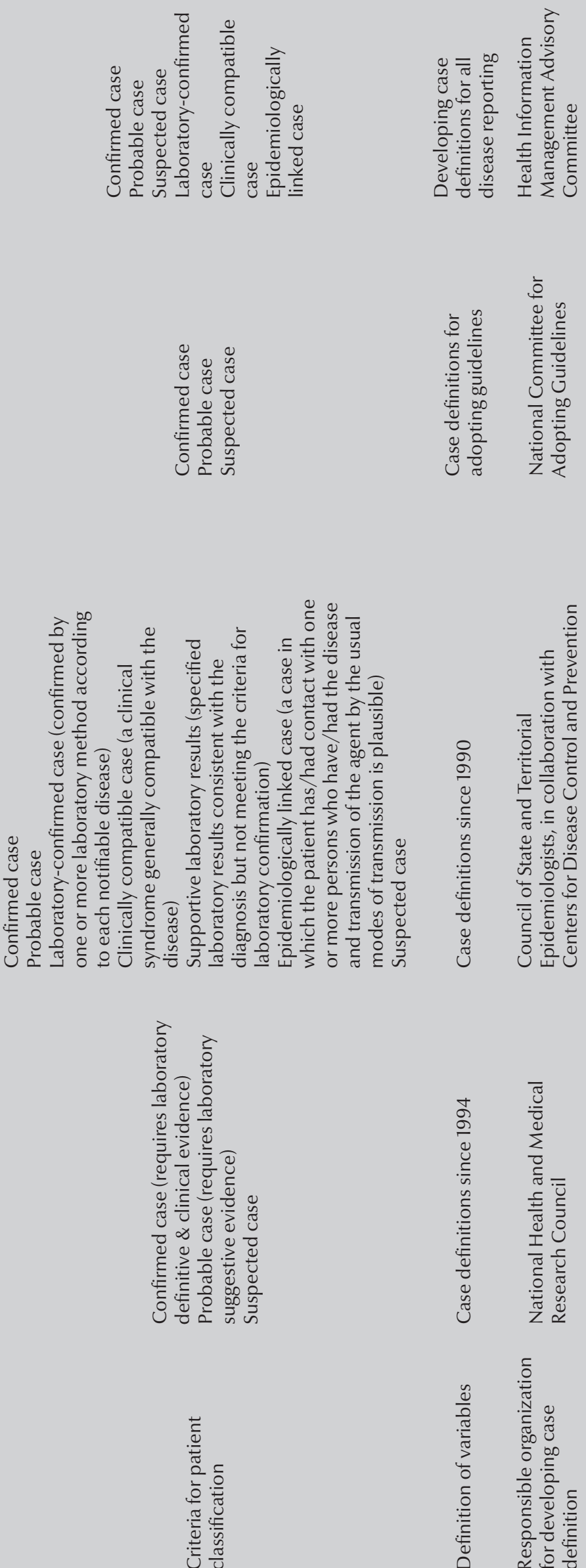

to diagnose medical conditions are issued with current lists of notifiable diseases that they are obliged by law to report to the appropriate authorities (Table 2).

\section{Case classification and definition}

Table 3 indicates that the USA describes more criteria for case classification than Australia. Australia and the USA both considered case definition as variables. The USA and Australia use the following common criteria for case classification.

- Suspected: a case with clinically compatible illness or meets the clinical case definition without laboratory testing, or a case with laboratory tests suggestive of the disease without clinical information.

- Probable: a case that meets the clinical case definition without laboratory confirmation and is epidemiologically linked to a clinically compatible case.

- Confirmed: a case that meets the clinical case definition or has clinically compatible illness; is indicated by supportive laboratory results consistent with the diagnosis; is either laboratory-confirmed or is epidemiologically linked to a confirmed case; and supportive laboratory results (in the USA).

\section{Proposed model for Iranian notifiable infectious diseases surveillance system}

After consolidation of the data collected in this study and a detailed review of the research and reports on information management for health units, an outline for a new Iranian notifiable diseases surveillance system is proposed.

For ease of comparison, details of the proposed system are listed in the fourth columns of Tables 1-3. Figure 1 represents the proposed organizational structure for the Iranian notifiable infectious diseases surveillance system. 


\section{Discussion}

In all 3 countries analysed, most notifiable diseases are reported initially to the local county or regional health department, from where the data are transferred to the national surveillance institution [3]. It is therefore important to ensure that the data collected at different levels are consistent and comparable and that the interaction between the departments is effective. Effective surveillance demands uniformity, simplicity and standardization of case definitions and classification.

While case definitions are intended to establish uniformity in disease reporting, they should not be used as the sole criteria for establishing clinical diagnoses; the use of additional clinical factors including epidemiological and laboratory data, may enable a physician to diagnose a disease even though the surveillance case definition may not be available $[11,12]$. Therefore, in the proposed revised Iranian model, the criteria "laboratory-confirmed cases" and "epidemiologically linked cases" have been added to the established items for patient classification in the notifiable infectious diseases surveillance system.

"Clinically compatible cases" are another set of criteria in which clinical symptoms are used to assign a case to a specific disease. These clinical descriptions give a general outline of the disease and do not necessarily indicate all the features needed for clinical diagnosis of the disease.

This survey indicates that the description of variables in both the USA and Australian national notifiable diseases surveillance systems are given according to case definitions. Iranian health professionals suggested that the American disease classification system would be appropriate for an Iranian notifiable infectious diseases surveillance system.
It is desirable that all the different agencies and stakeholders which are involved in the registration, reporting, diagnosis, treatment and publication of data concerning nationally notifiable diseases are involved in the surveillance system. One of the main limitations of the US surveillance system is the optional reporting of nationally notifiable diseases to the CDC by individual states.

A disease surveillance system is only 1 of the 5 interrelated subsystems of an effective health information management system and the knowledge and skills of a health information management professional could be useful in supporting its different components (data collection, transmission, processing and analysis) [13]. One outcome of using the Delphi method to rationalize the information gathered in this study was the decision that it would be advisable to ensure that the Iranian Office of Health Information Management, along with the Office of Communicable and Non-Communicable Diseases, would be responsible for formulating related policies and procedures. In this framework, establishing the Health Information Management Advisory Committee as a sub-committee of the Deputy of Health is recommended. These modifications are required to enhance the disease control systems. WHO has concentrated its action on the establishment of national departments and agencies in order to coordinate various activities of surveillance systems and well-organized disease control systems.

A standard classification of diseases is a necessary adjunct to an accurate notifiable infectious diseases surveillance system for data comparability at the national and international level. Therefore the use of the International classification of diseases (ICD), or a variation of it, is advisable and the Islamic Republic of Iran is currently working on a modified version of the ICD [14]. Routine notifiable disease surveillance often suffers from incomplete reporting; hence not only case definition and classification of diseases are important but the addition of other of data sources (e.g. coded discharge diagnoses or pharmacy dispensing data) is required to improve the sensitivity of routine notifiable disease surveillance. Implementation of these methods often depends on the existence of tables linking the laboratory or clinical codes to the notifiable conditions under surveillance. The Systematized Nomenclature of Medicine (SNOMED) and Logical Observation Identifier Names and Codes (LOINC) have been identified as important vocabulary standards for creating these tables. They should be considered for further development in the Iranian context [15].

It is important that data be collected and processed efficiently in order to meet time requirements for swift action when a notifiable disease is detected in the community. It is also crucial that data are easily interpreted and used in various ways without compromising patient confidentiality. Computerized surveillance systems in conjunction with the common use of the Internet and different methods of information distribution and dissemination are useful to ensure that relevant and updated surveillance information is always available at any time and place [16]. In this regard, the proposed model involves the use of a number of methods of distribution of information (Internet, facsimile, telephone, email, postal mail). An increasing demand for detailed data and an ambition to present care providers with more timely, consolidated information that can be a basis for preventive and therapeutic action are the driving forces behind the proposal to use modern web technology and geographical information systems (GIS) software in the Iranian system. 


\section{References}

1. Behebani AM. The smallpox story: life and death of an old disease. Microbiological Review, 1983, 47(4):455-509.

2. Brabazon ED et al. Under-reporting of notifiable infectious disease hospitalizations in a health board region in Ireland: room for improvement? Epidemiology and Infection, 2008, 136(2):241-247.

3. Krause G, Ropers G, Stark K. Notifiable disease surveillance and practicing physicians. Emerging Infectious Diseases, 2005, 11(3):442-445.

4. Vaughan P, Morrow RH, eds. Manual of epidemiology for district health management. Geneva, World Health Organization, 1994.

5. Asadi-Lari $M$ et al. Public health improvement in Iran: lessons from the last 20 years. Public Health, 2004, 118(6):395-402.

6. Esteghamati A et al. Progress in measles and rubella elimination in Iran. Pediatric Infectious Disease Journal, 2007, 26(12):11371141.

7. Reproductive health: glossary. Centers for Disease Control and Prevention [website] (http://www.cdc.gov/reproductivehealth/EpiGlossary/glossary.htm, accessed 25 March 2010).

8. Garson DG. Guide to writing empirical papers, theses, and dissertations. Boca Raton, Florida, CRC Press; 2001.

9. Research methods knowledge base. Descriptive statistics. Web Centre for Social Research Methods [website] (http://www. socialresearchmethods.net/kb/statdesc.php, accessed 25 March 2010).
10. WHO country office for the Islamic Republic of Iran. Programmed areas. Communicable disease surveillance. World Health Organization [website] (http://www.emro.who.int/iran/programmeareas-cdc.htm, accessed 25 March 2010).

11. Chaulagai $\mathrm{CN}$ et al. Design and implementation of a health management information system in Malawi: issues, innovations and results. Health Policy and Planning, 2005, 20(6):375384.

12. Case definitions for infectious conditions under public health surveillance. Morbidity and Mortality Weekly Report, 1997, 46(RR10):1-55.

13. Lippeveld R, Sauerborn R, Bodart C, eds. Design and implementation of health information management systems. Geneva, World Health Organization, 2000.

14. Safdari R, Meidani Z. Developing a model for an Iranian Classification of Diseases (IRCD) compatible with other adaptations of the International Classification of Diseases. Health Information Management Journal, 2007, 36(1):36-41.

15. Doyle TJ et al. PHSkb: a knowledgebase to support notifiable disease surveillance. BMC Medical Informatics and Decision Making, 2005, 5:27 (doi: 10.1186/1472-6947-5-27).

16. Rolfhamre P, Grabowska K, Ekdahl K. Implementing a public web based GIS service for feedback of surveillance data on communicable diseases in Sweden. BMC Infectious Diseases, 2004, 4:17 (doi: 10.1186/1471-2334-4-17).

\section{Eastern Mediterranean Regional Health System Observatory}

The primary purpose of Eastern Mediterranean Regional Health System Observatory is to promote evidence-based health policy-making by providing relevant and comparative information about health systems and reforms and to assist policy-makers in development of health systems in their countries. The aim is to contribute to improvement of health system performance and outcomes in countries of the Region.

The Observatory will also monitor and evaluate the attainment of critical outcomes and the efficiency of the health system in a way to allow comparison over time and across systems thus empowering policy-makers and build an evidence base on the relationship between the design of the health system and its performance.

Information about the Eastern Mediterranean Regional Health System Observatory can be found at: http://gis.emro. who.int/HealthSystemObservatory/Main/Forms/Main.aspx 